\title{
REGIONAL ROUGHNESS OF THE LANDES FOREST \\ AND SURFACE SHEAR STRESS UNDER \\ NEUTR A L CONDITIONS
}

\author{
MARC B. PARLANGE and WILFRIED BRUTSAERT \\ School of Civil and Environmental Engineering, Hollister Hall, Cornell University, Ithaca, \\ NY 14853-3501, U.S.A.
}

(Received in final form 21 November, 1988)

\begin{abstract}
Mean wind velocity profiles were measured by means of radio-windsondes over the Landes region in southwestern France, which consists primarily of pine forests with scattered villages and clearings with various crops. Analysis of neutral profiles indicated the existence of a logarithmic layer between approximately $z-d_{0}=67( \pm 18) z_{0}$ and $128( \pm 32) z_{0}\left(z\right.$ is the height above the ground, $z_{0}$ the surface roughness and $d_{0}$ the displacement height). The upper limit can also be given as $z-d_{0}=0.33$ $( \pm 0.18) h$, where $h$ is the height of the bottom of the inversion. The profiles showed that the surface roughness of this terrain is around $1.2 \mathrm{~m}$ and the displaccment height $6.0 \mathrm{~m}$. Shear stresses derived from the profiles were in good agreement with those obtained just above the forest canopy at a nearby location with the eddy correlation method by a team from the Institute of Hydrology (Wallingford, England).
\end{abstract}

\section{Introduction}

The hydrodynamic nature of land surfaces covered with vegetation is commonly characterized by the roughness length $z_{0}$, and by the (zero-plane) displacement height $d_{0}$. These two parameters arise in the logarithmic wind-profile equation, which is usually written as

$$
V=\frac{u_{*}}{k} \ln \left(\frac{z-d_{0}}{z_{0}}\right),
$$

where $V$ is the mean wind speed, $u_{*}=\left(\tau_{0} / \rho\right)^{1 / 2}$ the friction velocity, $\tau_{0}$ the surface shear stress, $\rho$ the density of the air, $z$ the height above the base level of the surface roughness obstacles and $k=0.4$ von Karman's constant. Equation (1), which was probably first applied to atmospheric flows by Prandtl (1932), is generally accepted to hold in the surface layer or inner region of the atmospheric boundary layer (ABL) under neutral conditions. Although neutral conditions in the atmosphere are the exception rather than the rule, the logarithmic equation has received considerable attention over the years, because it embodies turbulent momentum transport in its simplest form; it may thus be the basis or the starting point for the analysis of flows in which effects of density stratification and other complicating factors are important. In spite of all this attention, the usefulness of (1) and especially the height range of its validity over natural terrain with large roughness are not yet well understood. This was brought out, for example, in the discussion of wind profiles above forest by Hicks et al. (1979), Raupach et al. (1979) and Garratt (1979). 
In what follows, this issue is dealt with through an analysis of wind velocity profiles in the neutral ABL above forest. The data were obtained from radiowindsonde measurements during a field experiment in southwestern France.

\section{Description of Experiment}

Site and Terrain. The experiment, which provided the data, was conducted at approximately $00^{\circ} 03^{\prime} \mathrm{W}, 44^{\circ} 08^{\prime} \mathrm{N}$ near Lubbon in the Department of the Landes in Aquitaine. The geographical region of the Landes is an extensive plain in the shape of a triangle approximately with its base at the Bay of Biscay, its vertex near Nerac, south of the Garonne and north of the Adour River. It is occupied mostly by pine forest in various stages of growth with scattered towns, clearings and some agricultural fields. Within a radius of about $10 \mathrm{~km}$ from the experimental site, roughly $65 \%$ of the area is occupied by forest. In the predominant wind direction at the site, the fetch of similar terrain extends all the way to the coast, which is some $80 \mathrm{~km}$ away.

Profile Measurements. During the summer of 1986 from May 6 through July 14 , some 405 rawinsonde flights were made to determine vertical profiles of mean wind speed, wind direction, temperature and specific humidity. The radiosondes used for these flights were of the type designed and produced for the research purposes of the National Center for Meteorological Research (CNRM) in Toulouse. The mean velocity and direction of the horizontal wind were derived by means of automatic radar tracking of sonde position. The vertical resolution of the wind measurements could be made as fine as $0.2 \mathrm{~s}$, but for the present analysis it was taken as $10 \mathrm{~s}$ or, for average rates of rise of the balloon of $5 \mathrm{~m} / \mathrm{s}$, approximately $50 \mathrm{~m}$.

For operational purposes, days were categorized as "normal" or "favorable", depending on the weather conditions. On normal days, four sondes were launched, at $0000,0600,1200$, and 1800 UT (GMT). On favorablc days (i.c., undisturbed sunny conditions, with large surface fluxes of net radiation, latent and sensible heat, and with a well defined boundary-layer evolution), soundings were carried out at $0000,0600,0800,1000,1200,1400,1600$, and 1800 UT. Because of the small longitude of the site, the Universal Time (UT) is practically local solar time as well.

These measurements were made jointly by field crews from CNRM and from Cornell University as part of HAPEX-MOBILHY (Hydrologic Atmospheric Pilot Experiment-Modelisation du Bilan Hydrique). This was a common effort of several French agencies in meteorology and agronomy, under sponsorship of the WMO (World Meteorological Organization, 1985) in the World Climate Program (WCP), and with participation of research teams from the United States, Great Britain and the Netherlands. The overall objective of HAPEX-MOBILHY was the study of the hydrologic budget, evaporation and related fluxes at a scale of $10^{4} \mathrm{~km}^{2}$. The details of HAPEX-MOBILHY have been described by André $e t$ 
al. (1986) and some early results have been reported by André et al. (1988) (See also Brutsaert et al., 1988).

The friction velocity values derived from the rawinsonde wind profiles will be compared herein with momentum flux values measured directly just above the forest canopy. Approximately $4.5 \mathrm{~km}$ to the southwest of the launch site, a surface flux station was operated during the experiment by a research team (Drs. J. H. C. Gash, C. R. Lloyd and W. J. Shuttleworth) from the Institute of Hydrology, Wallingford, Great Britain. At this station, several meteorological variables were recorded on top of a $25 \mathrm{~m}$ tower, which was surrounded by fairly uniform forest with tree heights of about $20 \mathrm{~m}$ in all directions for approximately $750 \mathrm{~m}$. At a height of $29 \mathrm{~m}$ above the ground, an eddy correlation flux system was placed on a mast fastened to the tower. This system which has been described elsewhere (Shuttleworth et al., 1984; 1988) produced hourly averages of friction velocity, sensible heat flux and water vapor flux just above the trees.

Neutral Wind Profile Data. Neutral conditions require that the density of the air be constant with elevation, and that the production of turbulent kinetic energy due to surface shear stress be large compared to that due to surface heat fluxes. A reliable measure of the density of the air is the virtual potential temperature,

$$
\theta_{v}=\theta(1+0.61 q)
$$

where $\theta$ is the potential temperature and $q$ the specific humidity. Strong wind is usually an indication of large surface shear stress, and the surface heat fluxes tend to be smaller under cloudy conditions. Thus, an initial identification of neutral conditions was made on the basis of the general constancy of the vertical $\theta_{v}$-profile, and on the basis of the prevailing weather, viz., windy and/or cloudy conditions.

The selection was then subsequently tested by means of Obukhov's length $L$ and by means of Pasquill's (1961) stability class. The Obukhov length is defined by

$$
L=\frac{-u_{*}^{3}}{k g\left[H_{v} /\left(\rho c_{p} T_{a}\right)\right]},
$$

where $g$ is the acceleration of gravity, $c_{p}$ the specific heat of air at constant pressure, $T_{a}$ a reference air temperature near the ground, $H_{v}=\left(H+0.61 T_{a} c_{p} E\right)$ the virtual sensible heat flux, $H$ the turbulent sensible heat flux at the surface and $E$ the rate of surface evaporation. For the present purpose, the $L$-values were calculated for each flight by means of $u *$ obtained from the wind profiles (see below) and of $H_{v}$ obtained from measurements both at the eddy correlation station of the Institute of Hydrology above the forest and at the energy budget stations of the CNRM (e.g., André et al., 1988) in the agricultural clearing at the launch site.

The stability classification system of Pasquill (1961) requires wind speed near the ground and insolation. It was developed over terrain with smaller roughness 
TABLE I

Criteria for neutrality

\begin{tabular}{llllll}
\hline $\begin{array}{l}\text { Flight } \\
\text { Number }\end{array}$ & \multicolumn{2}{l}{ Obukhov $L(\mathrm{~m})$} & $\begin{array}{l}\Delta \theta_{v} \\
\left(10^{-3}{ }^{\circ} \mathrm{C} / \mathrm{m}\right) \\
\text { for lowest } 50 \mathrm{~m}\end{array}$ & $\begin{array}{l}\text { Pasquill } \\
\text { Class }\end{array}$ & Sky \\
\cline { 2 - 5 } & Forest & Clearing & & \\
\hline 156 & & -2378 & +2.09 & $\mathrm{D}$ & Overcast, cumulus $8 / 8$. \\
157 & & -3781 & -1.22 & $\mathrm{D}$ & Overcast, cumulus $8 / 8$. \\
238 & -1536 & 10058 & +0.68 & $\mathrm{D}$ & Overcast, altostratus $8 / 8$ \\
269 & -688 & -860 & +0.56 & $\mathrm{D}$ & Cumulus 4/8. \\
277 & -170 & -287 & -8.06 & $\mathrm{D}$ & Cirrus 5/8. \\
303 & -2638 & -899 & +1.71 & $\mathrm{D}$ & Stratus 8/8. \\
320 & -255 & -299 & -4.71 & $\mathrm{D}$ & Altocumulus 4/8. \\
340 & 670 & 1073 & +3.20 & $\mathrm{D}$ & Altocumulus 5/8. \\
\hline
\end{tabular}

Note: D: neutral.

than forest, so that the wind speed classes should be adjusted to the present setting. This can be done by assuming that Pasquill's experiments had roughness lengths of the order of $0.01 \mathrm{~m}$ and that the winds were measured at a height of $10 \mathrm{~m}$; for the present purpose, the winds at $40 \mathrm{~m}$ above the ground were used, and the roughness of forest is known to be of the order of $z_{0}=1 \mathrm{~m}$ (see below). Hence, if $V_{L}$ is the wind velocity of the present study and $V_{P}$ that in Pasquill's scheme, with (1) one obtains the ratio $V_{L} / V_{P}=\ln (40 / 1.0) / \ln (10 / 0.01)=0.53$. This shows that, under similar conditions of insolation, the wind speeds above the Landes forest can be roughly $50 \%$ smaller than the ones defining Pasquill's classes and still define the same class.

The outcome of the application of these criteria, to the flights that were retained, is shown in Table I. It can be seen that in most cases, the four criteria indicated atmospheric conditions close to neutral. Thus, among the 405 flights, 8 were identified as being suitable for the analysis. Some other characteristics of the profiles are presented in Table II. As a further illustration of the neutrality of

TABLE II

\begin{tabular}{llllrl}
\hline $\begin{array}{l}\text { Flight } \\
\text { Number }\end{array}$ & $\begin{array}{l}\text { Date } \\
\text { Yr/Mo/Day }\end{array}$ & Time (UT) & $\begin{array}{l}\text { Inversion } \\
\text { Height }(\mathrm{m})\end{array}$ & $\begin{array}{l}\mathbf{V}_{100 \mathrm{~m}} \\
(\mathrm{~m} / \mathrm{s})\end{array}$ & $\begin{array}{l}\text { Wind Direction (at 100 m) } \\
\text { (Degrees from N) }\end{array}$ \\
\hline 156 & $86 / 6 / 05$ & 0531 & 279 & 5.8 & 239 \\
157 & $86 / 6 / 05$ & 1118 & 564 & 12.4 & 297 \\
238 & $86 / 6 / 17$ & 2321 & 434 & 7.3 & 267 \\
269 & $86 / 6 / 22$ & 1719 & 944 & 7.8 & 356 \\
277 & $86 / 6 / 23$ & 1724 & 1075 & 5.7 & 264 \\
303 & $86 / 6 / 27$ & 0539 & 294 & 7.9 & 245 \\
320 & $86 / 6 / 30$ & 1712 & 1336 & 5.7 & 299 \\
340 & $86 / 7 / 04$ & 2312 & 253 & 4.2 & 298 \\
\hline
\end{tabular}




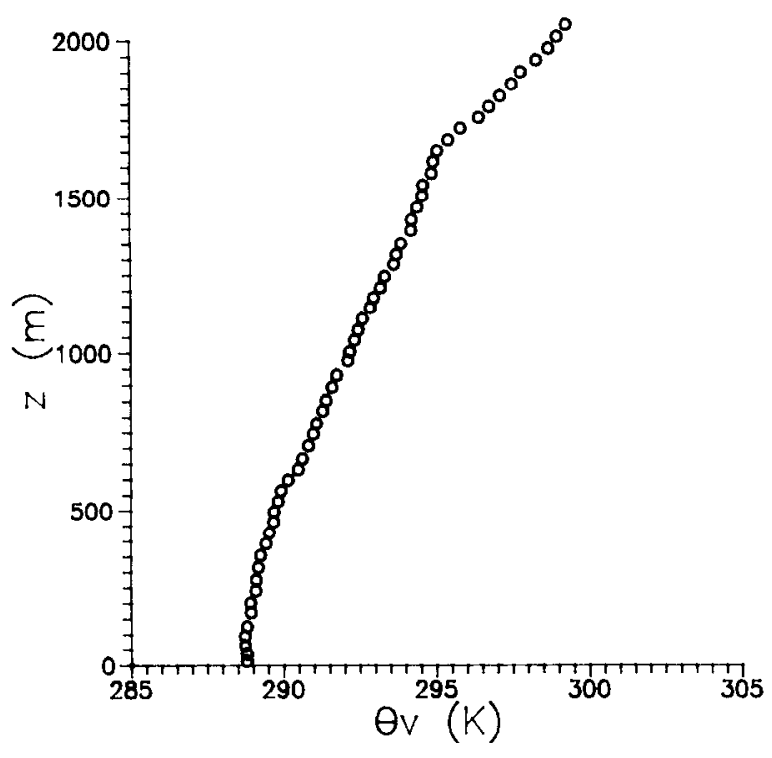

Fig. 1. Profile of the virtual potential temperature recorded during Flight 157.

these flights, two virtual potential temperature profiles are shown in Figures 1 and 2 .

\section{Analysis}

Displacement Height. For any given situation, (1) contains 3 unknown parameters, viz., $u_{*}, z_{0}$ and $d_{0}$. If (1) truly describes the mean wind velocity

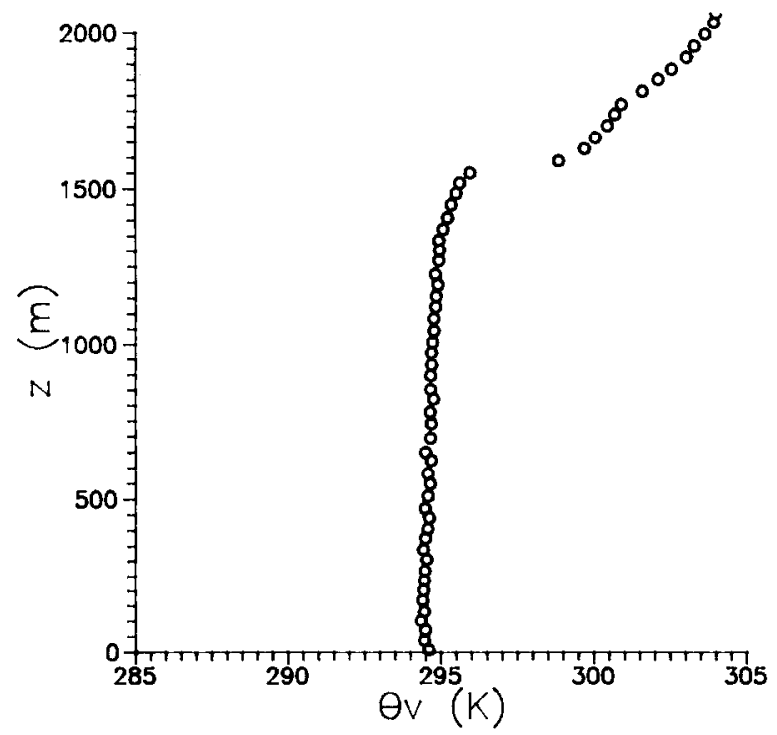

Fig. 2. Profile of the virtual potential temperature for Flight 320. 
profile, it should be possible to determine these parameters from the profile obscrvations. However, rawinsonde data are usually quite noisy as a result not only of turbulence (i.e., short-term sampling) but also of instrumental error (see also Kustas and Brutsaert, 1986). Therefore it is desirable to reduce the number of unknown parameters to the absolute minimum and to constrain the equation to ensure proper behavior. Relative changes in the displacement height $d_{0}$ affect the performance of (1) less than relative changes in $z_{0}$ and $u *$. Moveover, $d_{0}$ can be related to the physical characteristics of the surface. For densely placed porous roughness obstacles such as trees and similar types of vegetation, it has been found in many studies (see Brutsaert, 1982; for coniferous forest, see Jarvis et al., 1976) that it is equal to a fraction between 0.5 and 1.0 of the height $h_{0}$ of the obstacles. A good consensus is

$$
d_{0}=2 h_{0} / 3 \text {. }
$$

However, for the region of the Landes with forests in different stages of growth and with scattered clearings and population centers, $h_{0}$ is difficult to determine. I his difficulty can be avoided by expressing $d_{0}$ in terms of $z_{0}$. For vegetational surfaces, Paeschke (1937) found

$$
z_{0}=h_{0} / c_{r}
$$

with $c_{r}=7.5$, to give a good description of the data; this has been confirmed in numerous experiments (for a review, see Brutsaert, 1982) with values of $c_{r}$ generally of the order of about 10 . Thus combination of (4) and (5) yields

$$
d_{0}=C_{0} z_{0}
$$

where $C_{0}$ should be of the order of 5 to 7 .

Calculation of $u *$ and $z_{0}$. Substitution of (6) with $C_{0}=5$ into (1) produces

$$
V=\frac{u *}{k} \ln \left(\frac{z-5 z_{0}}{z_{0}}\right),
$$

which contains only 2 unknown parameters $u_{*}$ and $z_{0}$. Equation (7) can readily be solved by iteration for a given observed wind profile; an initial value of $z_{0}$ is assumed in the numerator of the log term, after which $u_{*}$ and $z_{0}$ in the denominator are determined from the least-squares regression line of $V$ on $\ln \left(z-5 z_{0}\right)$. The new value of $z_{0}$ is then placed in the numerator and the process is repeated. The procedure converges rapidly.

In carrying out this procedure, a question arises: Which points of the measured profile should be used in the regression? In other words, over what range of $z$-values is the logarithmic equation appropriate to describe the $V$-profile? In the present study, this was resolved by selecting by trial and error the maximal number of data points that would yield a reasonable value of $z_{0}$. "Reasonable" in this context was taken to mean any value of $z_{0}$ in the range between 0.5 and $2.0 \mathrm{~m}$; this is the range that could normally be expected for the type and size of 


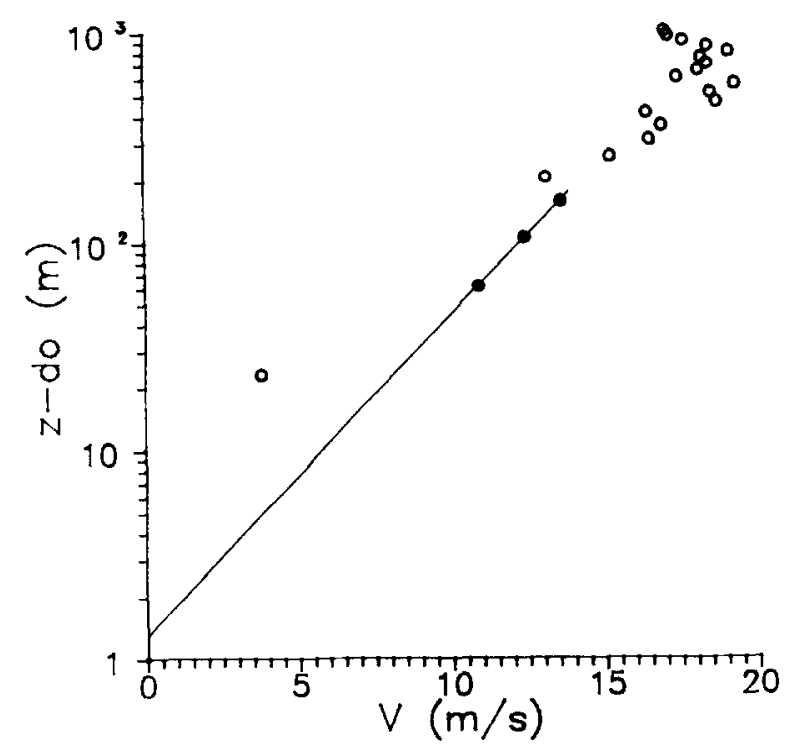

Fig. 3. Profile of the horizontal wind velocity recorded during Flight 157. The straight line is the least squares regression through the solid points.

roughness elements in the Landes forest. In most cases, this worked well because addition of one more point outside the selected interval below or above the chosen range, resulted in values of $z_{0}$ drastically different from what could normally be expected for sparse pine forest. In some cases, the choice of the highest point of the $z$-range was further facilitated by the fact that the wind profile displayed marked changes in direction above it.

Figures 3 and 4 show examples of the wind velocity profile data used in the analysis. Flight 157 is one of the better data sets because 3 points were found to be in the logarithmic layer; Flight 320 is marginal in this respect, since only 2 points were usable.

\section{Results}

Table III shows the values of $u_{*}$ and $z_{0}$ calculated by least-squares linear regression of (7), together with the height range of the selected points for each of the 8 neutral flights. The geometric and the arithmetic means both are $z_{0}=$ $1.2 \mathrm{~m}$, and thus $d_{0}\left(=5 z_{0}\right)=6.0 \mathrm{~m}$. The mean range of validity of $(7)$ is $86 \pm$ $22 \mathrm{~m} \leq z \leq 160 \pm 38 \mathrm{~m}$. Also shown in the last column of Table III are the valucs of $u_{*}$ calculated by means of $(7)$ for $z_{0}=1.2 \mathrm{~m}$, i.e., by regression with an imposed intercept. It can be seen that these values are very similar to the values in the sixth column.

Figure 5 shows a plot of the data points below $1,000 \mathrm{~m}$ for all 8 profiles made dimensionless by means of these $u *$ values and with $z_{0}=1.2 \mathrm{~m}$ and $d_{0}=6 \mathrm{~m}$. 


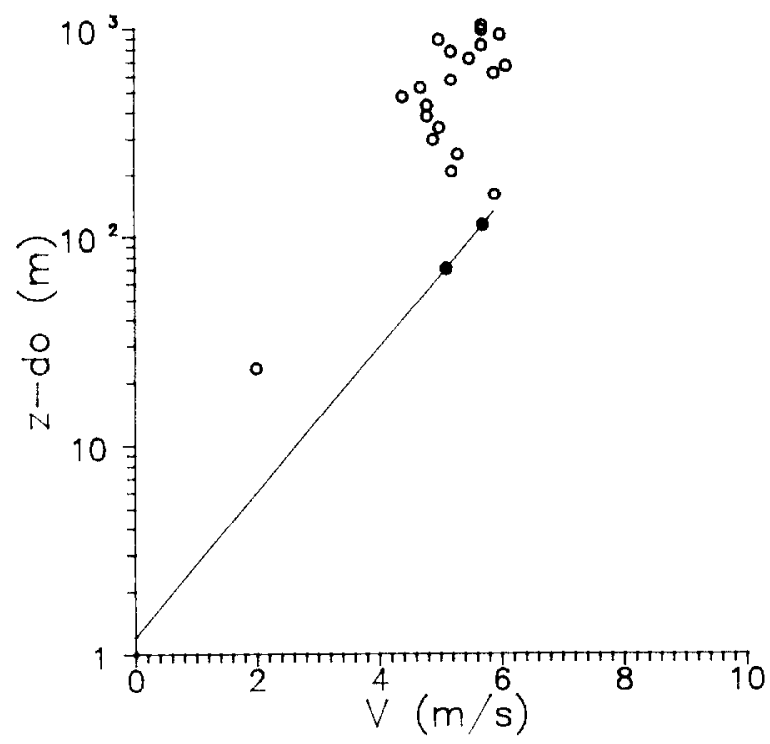

Fig. 4. Same as Figure 3 for Flight 320.

Figure 6 is the same plot; however, the only data points shown are those used in the linear regression with (7) to derive the $z_{0}$ and $u_{*}$ values. Comparison of these figures suggests that while the logarithmic layer can be scaled well by means of $u *$ and $z_{0}$, these parameters are not adequate to scale the outer region of the ABL even under neutral conditions.

\section{Concluding Summary}

The analysis of the neutral rawinsonde wind profiles produced a mean roughness of $z_{0}=1.2 \mathrm{~m}$ for the Landes region. This is certainly within the range of values to

TABLE III

\begin{tabular}{lllllll}
\hline $\begin{array}{l}\text { Flight } \\
\text { Number }\end{array}$ & $\begin{array}{l}\text { Range of } \\
z(\mathrm{~m})\end{array}$ & $\begin{array}{l}\text { No. of } \\
\text { Points }\end{array}$ & $\begin{array}{l}z_{0} \\
(\mathrm{~m})\end{array}$ & $\begin{array}{l}d_{0} \\
\left(=5 z_{0}\right) \\
(\mathrm{m})\end{array}$ & $\begin{array}{l}u_{*} \\
\text { for variable } \\
z_{0} \text { and } d_{0} \\
(\mathrm{~m} / \mathrm{s})\end{array}$ & $\begin{array}{l}u_{*} \\
\text { for } z_{0}=1.2 \\
\text { and } d_{0}=6.0 \\
(\mathrm{~m} / \mathrm{s})\end{array}$ \\
\hline 156 & & & & & & \\
157 & $77-130$ & 2 & 1.20 & 6.02 & 0.57 & 0.57 \\
238 & $67-164$ & 3 & 1.30 & 6.52 & 1.13 & 1.11 \\
269 & $111-236$ & 4 & 0.84 & 4.18 & 0.60 & 0.64 \\
277 & $124-170$ & 2 & 0.74 & 3.72 & 0.61 & 0.68 \\
303 & $89-185$ & 3 & 1.66 & 8.30 & 0.59 & 0.55 \\
320 & $59-146$ & 3 & 1.93 & 9.67 & 0.86 & 0.76 \\
340 & $76-119$ & 2 & 1.22 & 6.11 & 0.50 & 0.50 \\
Mean & $84-131$ & 2 & 0.98 & 4.87 & 0.35 & 0.36 \\
& $86-160$ & 3 & 1.18 & 6.0 & 0.65 & 0.65 \\
\hline
\end{tabular}




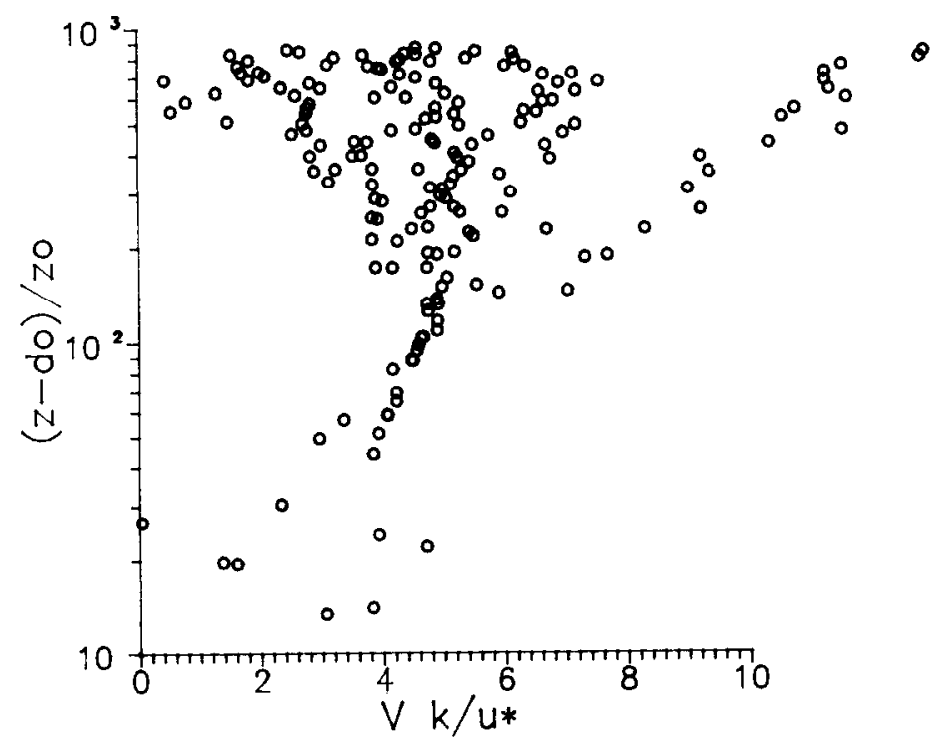

Fig. 5. Composite dimensionless plot of all the wind velocity data points for the 8 neutral flights listed in Table II. The data are scaled with $z_{0}=1.2 \mathrm{~m}$ and $d_{0}=6.0 \mathrm{~m}$.

be expected for this type of forest. For example, with Paeschke's equation (5), this $z_{0}$ value suggests an effective height of the roughness obstacles of $h_{0}=9$ to $12 \mathrm{~m}$. As noted earlier, $65 \%$ of the region is covered by forest sections in different stages of growth, the heights of the trees ranging roughly between 1 and $20 \mathrm{~m}$; the remainder is occupied by clearings and agricultural fields and some

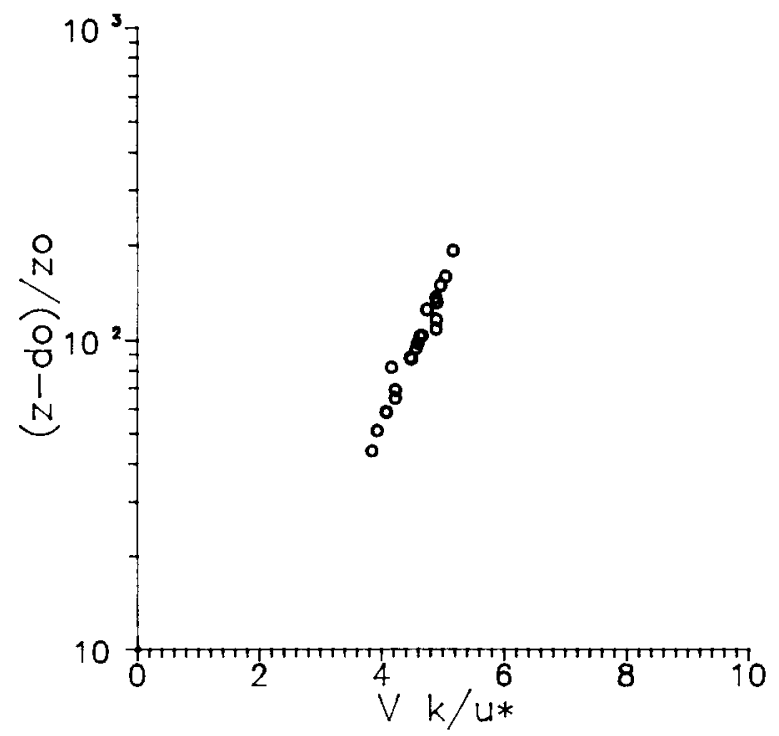

Fig. 6. Same dimensionless plot of the wind velocity data as in Figure 5 but showing only the points used in the analyses to derive $z_{0}$ and $u_{*}$. 
housing. Hence an intermediate height $h_{0}$ of around $10 \mathrm{~m}$ is not unreasonable.

The height range, over which (1) and (7) arc valid, can also be cxpressed in dimensionless form as $67( \pm 18) \leq\left(z-d_{0}\right) / z_{0} \leq 128( \pm 32)$. This range is consistent with the range observed by Brutsaert and Kustas (1985) in the Fore-Alpine region of Switzerland for the logarithmic humidity profile under neutral conditions, namely $50 \leq\left(z-d_{0}\right) / z_{0} \leq 135$. The lower limit of the logarithmic layer is also consistent with previous estimates. For example, Garratt $(1978,1980)$ concluded from experimental data that the lower height of the logarithmic layer above tree-covered terrain, expressed as $\left(z-d_{0}\right) / z_{0}$ was 35 at a densely vegetated site and 150 at a less dense site. Similar values can be derived from the velocity data measured by Raupach et al. (1980) above bluff-rough obstacles in a windtunnel; the lower limit was 25 for placement densities of $\lambda=0.18$ and 0.091 , it rose to 51 for $\lambda=0.046$ and to 97 for $\lambda=0.023$. Finally, Townsend (1976) felt that the lower limit should lie around $z / z_{0}=50$, while Tennekes (1973) suggested, admittedly arbitrarily, that it probably is of the order of $z / z_{0}=100$.

The upper limit of the logarithmic layer can also be expressed in terms of the height of the boundary layer. The data in Tables II and III yield an average ratio $\left(z-d_{0}\right) / h=0.33( \pm 0.18)$. This is considerably higher than the value of $10 \%$ which is often taken as the thickness of the surface layer of a turbulent boundary layer. This is a confirmation of the earlier findings of Kustas and Brutsaert (1986) in the rugged terrain of the Swiss Fore-Alps. Evidently the rule-of-thumb of $10 \%$ is only applicable to surfaces with smaller roughness.

To illustrate the reliability of the present $u_{*}$ values, 6 (of the 8 ) are compared in Figure 7 with the values measured some $4.5 \mathrm{~km}$ away by the eddy-correlation

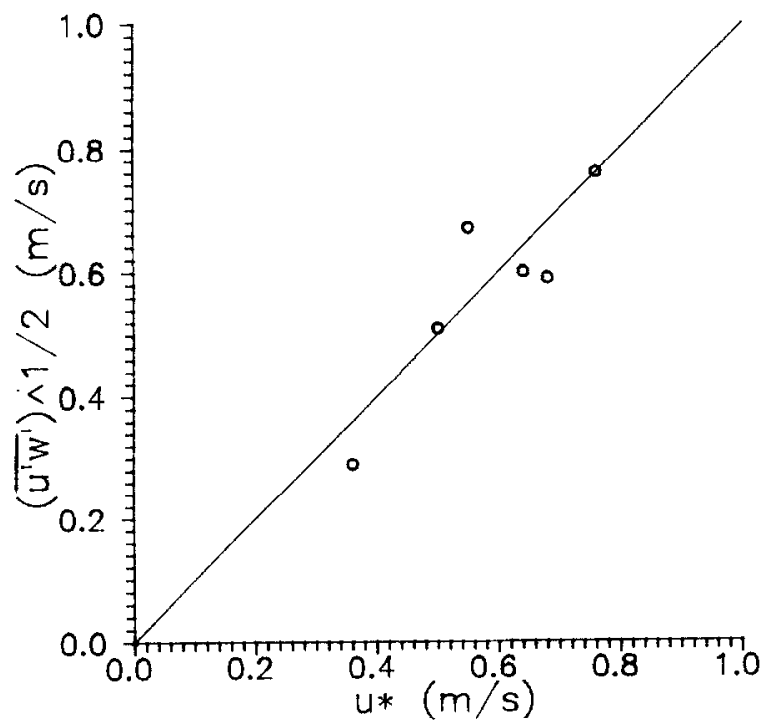

Fig. 7. Comparison between the $u_{*}$ values derived from 6 wind profiles for $z_{0}=1.2 \mathrm{~m}$ with the $\frac{\left(u^{\prime} w^{\prime}\right.}{1 / 2}$ values measured some $4.5 \mathrm{~km}$ away by means of the eddy correlation method $9 \mathrm{~m}$ above the tree tops. The correlation coefficient is $r=0.88$. 
TABLE IV

Additional flights near neutral

\begin{tabular}{|c|c|c|c|c|c|c|c|}
\hline $\begin{array}{l}\text { Flight } \\
\text { Number }\end{array}$ & $\begin{array}{l}\text { Date } \\
\text { Yr./Mo./Day }\end{array}$ & $\begin{array}{l}\text { Time } \\
\text { (UI) }\end{array}$ & $\begin{array}{l}L(\mathrm{~m}) \\
\text { (forest) }\end{array}$ & $\begin{array}{l}\Delta \theta_{v} \\
\text { for lowest } \\
50 \mathrm{~m} \\
\left(10^{-3}{ }^{\circ} \mathrm{C} / \mathrm{m}\right)\end{array}$ & Pasquill & Sky & $\begin{array}{l}u_{*}(\mathrm{~m} / \mathrm{s}) \\
\left(z_{0}=1.2 \mathrm{~m}\right) \\
\left(d_{0}=6 \mathrm{~m}\right)\end{array}$ \\
\hline 203 & $86 / 6 / 11$ & 1740 & -950 & -0.88 & D & overcast $8 / 8$ & 0.78 \\
\hline 221 & $86 / 6 / 14$ & 1724 & -566 & -1.91 & D & overcast $8 / 8$ & 0.32 \\
\hline 232 & $86 / 6 / 16$ & 0757 & -203 & -11.34 & $\mathrm{C}$ & clear & 0.80 \\
\hline 239 & $86 / 6 / 17$ & 0519 & -2680 & -0.28 & D & overcast $8 / 8$ & 0.41 \\
\hline 241 & $86 / 6 / 17$ & 1733 & -1885 & -8.41 & D & overcast $8 / 8$ & 0.40 \\
\hline 272 & $86 / 6 / 23$ & 0740 & -12278 & -8.7 & D & cumulus $4 / 8$ & 1.29 \\
\hline
\end{tabular}

Note: D Neutral; C Slightly unstable.

method on the mast of the Institute of Hydrology at $9 \mathrm{~m}$ above tree top level. (The eddy-correlation system was in operation for $2 / 3$ of the radiosounding experimental period). The agreement is remarkable with a correlation coefficient of $r=0.88$ and a slope of the regression line through the origin of 0.98 .

Not all the neutral wind profiles recorded during the experiment were suitable to determine $z_{0}$ in the present analysis. Indeed, the analysis requires high quality profiles, and in some cases the observed profile was too erratic or noisy to be usable. Nevertheless, once the value of $z_{0}$ is known, such profiles are usually still adequate to determine the value of $u_{*}$. Thus, beside the flights listed in Table I,

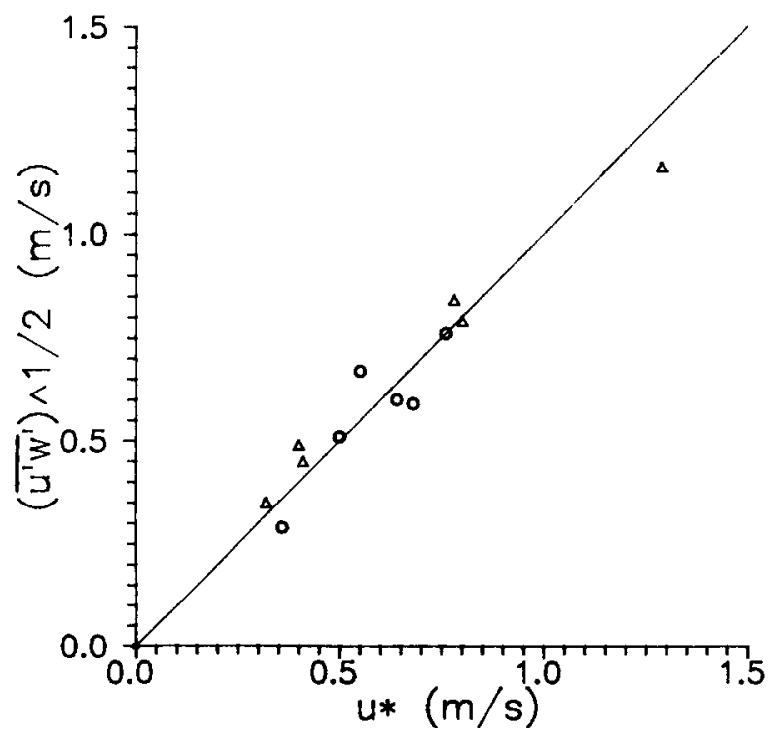

Fig. 8. Same as Figure 7 but with inclusion of 6 additional wind profiles (triangles) which were not used in the analysis to determine $z_{0}$. The correlation coefficient is $r=0.96$. 
some 6 additional ones could be used for this purpose. (See Table IV.) For these flights, $u *$ was determined by least squares linear regression of (7) through the data between roughly $z=80 \mathrm{~m}$ and $160 \mathrm{~m}$, for a fixed intercept of $z_{0}=1.2 \mathrm{~m}$. The resulting $u_{*}$ values, together with those obtained from the 6 good quality flights, are compared with $\left(\overline{u^{\prime} w^{\prime}}\right)^{1 / 2}$ values measured by the eddy correlation method on the $29 \mathrm{~m}$ mast. The correlation coefficient is 0.96 and the slope of the regression line through the origin is 0.98 .

Note that several other wind profiles were considered in this study. Flights 94 , $108,213,245,285$, and 366 were mildly non-neutral with $L$-values between -50 and -200 . Inclusion of these profiles in the analysis produced a geometric mean of the roughness of $z_{0}=1.16 \mathrm{~m}$. However, these results are not presented here.

\section{Acknowledgements}

The authors are grateful to J.-C. André and J. P. Goutorbe, of the CNRM in Toulouse, and to A. Perrier, of the INRA in Grignon, France, without whose inspiration and leadership the field experiment would not have been possible. The authors would also like to express their thanks to the members of the 4-M team of CNRM and others who were their helpful companions on the field crew, namely M. Payen (leader), P. Bergue, M. T. Bessières, G. Desroziers, C. Gerbier, E. Gizard, G. Lachaud, J. Noilhan, P. Péris, N. Raynal, C. Tarrieu, M. Tyteca. In addition, they would like to thank J. H. C. Gash, C. R. Lloyd and W. J. Shuttleworth of the Institute of Hydrology, Wallingford, Great Britain, who provided the eddy-correlation flux data, allowing the comparisons in Figures 7 and 8 .

This research has been supported and financed, in part, by the Division of Atmospheric Sciences of the National Science Foundation through grant ATM8601115 .

\section{References}

André, J.-C., Goutorbe, J.-P. and Perrier, A.: 1986, 'HAPEX-MOBILHY: A Hydrologic Atmospheric Experiment, for the Study of Water Budget and Fvaporation Flux at the Climate Scale', Bull. Am. Meteorol. Soc. 67, 138-144.

André, J.-C., Goutorbe, J.-P., Perrier, A. et al.: 1988, 'Evaporation Over Land-Surfaces; First Results From HAPEX-MOBILHY Special Observing Period', Annales Geophysicae 6(5), 477492.

Brutsaert, W.: 1982, Evaporation Into the Atmosphere, D. Reidel Publ. Co., Holland, 299 pp.

Brutsaert, W. and Kustas, W. P.: 1985, 'Evaporation and Humidity Profiles for Neutral Conditions over Rugged Hilly 'lerrain', J. C'limate Appl. Met. 24, 915-923.

Brutsaert, W., Schmugge, T. J., Sellers, P. J., and Hall, F. G.: 1988, 'Large-scale Experimental Technology with Remote Sensing in Land Surface Hydrology and Meteorology', Eos (Trans. AGU) 69(18), 561, 569-570.

Garratt, J. R.: 1978, 'Flux Profile Relations Above Tall Vegetation', Quart, J. Roy. Meteorol. Soc. 104, 199-211. 
Garratt, J. R.: 1979, 'Comments on the Paper "Analysis of the Flux-Profile Relationships Above Tall Vegetation - an Alternative View II"', Quart. J. Roy. Meteorol. Soc. 105, 1079-1082.

Garratt, J. R.: 1980, 'Surface Influence Upon Vertical Profiles in the Atmospheric Near-Surface Layer', Quart. J. Roy. Meteorol. Soc. 106, 803-819.

Hicks, B. B., Hess, G. D., and Wesely, M. L.: 1979, 'Analysis of Flux-Profile Relationships Above Tall Vegetation - An Alternative View', Quart. J. Roy. Meteorol. Soc. 105, 1074-1077.

Jarvis, P. G., James, G. B., and Landsberg, J. J.: 1976, 'Coniferous Forest, Chapter 7 in "Vegetation and the Atmosphere", J. L. Monteith (ed.), Vol. 2, Academic Press, London.

Kustas, W. P. and Brutsaert, W.: 1986, 'Wind Profile Constants in a Neutral Atmospheric Boundary Layer over Complex Terrain', Boundary-Layer Meteorol. 34, 35-54.

Paeschke, W.: 1937, 'Experimentelle Untersuchungen zum Rauhigkeits- und Stabilitaetsproblem in der Bodennahen Luftschicht', Beitr. $z$. Phys. d. Freien Atm. 24, 163-189.

Pasquill, F.: 1961, 'The Estimation of the Dispersion of Windborne Material', Meteorol. Mag. 90, 33-49.

Prandtl, L.: 1932, 'Meteorologische Anwendungen der Stroemungslehre', Beitr. Phys. Fr. Atm. 19, 188-202.

Raupach, M. R., Stewart, J. B., and Thom, A. S.: 1979, "Comments on the Paper "Analysis of Flux-Profile Relationships Above Tall Vegetation - an Alternative View" I', Quart. J. Roy. Meteorol. Soc. 105, 1077-1078.

Raupach, M. R., Thom, A. S., and Edwards, I.: 1980, 'A Wind-Tunnel Study of Turbulent Flow Close to Regularly Arrayed Rough Surfaces’, Boundary-Layer Meteorol. 18, 373-397.

Shuttleworth, W. J., Gash, J. H. C., Lloyd, C. R., Moore, C. J., Roberts, J., Marques, A. de O., Fisch, G., Silva, V. de P., Ribeiro, M. N. G., Molion, L. C. B., de Sa, L. D. A., Nobre, J. C., Cabral, O. M. R., Patel, S. R., and Moraes, J. C.: 1984, 'Eddy Correlation Measurements of Energy Partition for Amazonian Forest', Quart. J. Roy. Meteorol. Soc. 110, 1143-1162.

Shuttleworth, W. J., Gash, J. H. C., Lloyd, C. R., Moore, C. J., and Wallace, J. S.: 1988, 'An Integrated Micrometeorological System for Evaporation Measurement', Agric. and For. Meteorol., (in press).

Tennekes, H.: 1973, 'The Logarithmic Wind Profile', J. Atm. Sci. 30, 234-238.

Townsend, A. A.: 1976, The Structure of Turbulent Shear Flow, Sec. Ed., Cambridge University Press, $429 \mathrm{pp}$.

World Meteorological Organization: 1985, Report of the First Session of the JSC Scientific Steering Group on Land Surface Processes and Climate, (Geneva, 21-25 January, 1985), World Climate Program, WCP-96, 23 pp. + App. 